\title{
МОЛЕКУЛЯРНО-ГЕНЕТИЧЕСКОЕ ИССЛЕДОВАНИЕ ОЖИРЕНИЯ У ЖЕНЩИН
}

\author{
${ }^{1}$ Кочетова О.В., ${ }^{2}$ Авзалетдинова Д.Ш., ${ }^{2}$ Шангареева 3.А., ${ }^{1}$ Корытина Г.Ф. \\ ' Институт биохимии и генетики ФГБНУ «Уфимский федеральный исследовательский центр Российской академии \\ наук» (ИБГ УФИЦ РАН), Уфра \\ ${ }^{2}$ Башкирский государственный медицинский университет (БГМУ), Уфра
}

Ожирение возникает вследствие нарушения баланса между энергией, которую человек расходует, и энергией, которую получает с пищей. Это комплексная проблема обусловленная взаимодействием, как внешних факторов, так и генетической предрасположенностью, обусловленной полиморфными вариантами множества генов. На сегодняшний день не выясненной остается проблема генов, вовлеченных в формирование предрасположенности к ожирению.

ЦЕЛЬ: провести анализ ассоциаций у пациенток с ожирением по 10-полиморфным маркерам генов, отвечающих за формирование различных видов зависимости, относящихся к дофаминергической (DRD2) ANKK rs 1800497), серотонинергической (SLC6A4/NNTRrs28363170, HTR2A rs6313, rs6311, TPH2 rs4570625) и норадренергической системам (ADRA2A rs 1800544, rs553668, ADRB3 rs4994, ADRB1 rs1801253, rs1801252).

МАТЕРИАЛЫ И МЕТОДЫ: в исследовании были использованы образцы ДНК 1380 женщин, татарок по этнической принадлежности, проживающих на территории Республики Башкортостан. Из них группа испытуемых с ожирением 450 женщин и контрольная группа 444 индивида. Исследовано 10 полиморфных маркеров генов, отвечающих за формирование различных видов зависимости DRD2/ANKK rs1800497, SLC6A4/VNTRrs28363170, HTR2A rs6313, rs6311, TPH2 rs4570625, ADRA2A rs 1800544, rs553668, ADRB3 rs4994, ADRB1 rs1801253, rs1801252. Исследовали полиморфные локусы при помощи ПЦР с последующим расщеплением продукта соответствующими рестриктазами Mspl, Dral, Mspl, BstN I, Sau96 I, Mspl, Psil, Taql. Результаты амплификации и рестрикции оценивали при помощи вертикального электрофореза в 6-8\% полиакриламидном геле.

PEзУЛЬTATЫ: показано, что маркерами развития ожирения являются генотипы гена ADRA2A rs1800544 CG+GG OR=3,46 (Cl 95\% 1,52-7,89), $\mathrm{p}=0,0001$, гена ADRB3 rs4994CT+CC (OR=3,85 (Cl 95\% 2,49-

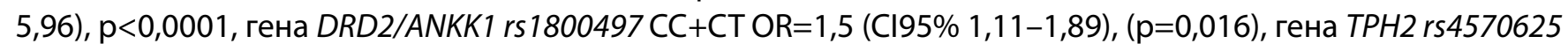

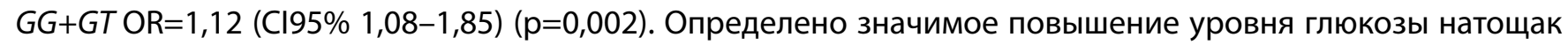
у индивидов с генотипами $A D R B 3 \mathrm{CT}+C \mathrm{C}(\mathrm{p}=0.007)$, высокие показатели глюкозотолерантного теста выявлены у носителей ADRB3rs4994CC ( $\mathrm{p}=0.000000004), A D R A 2 A$ rs $1800544 \mathrm{GC}+\mathrm{GG}(\mathrm{p}=0.0001)$, HTR2Ars6313CC ( $\mathrm{p}=0,038)$. Установлено, что повышенный уровень инсулина натощак определялся у носителей $A D R B 3$ rs4994 CC (p=0,047), ADRA2A rs1800544 GC+GG ( $=0,0006)$, высокий уровень индекса инсулинорезистентности HOMA-IR выявлен у носителей генотипа ADRB3 rs4994 CC (p=0,024), ADRA2A rs1800544 GC+GG $(\mathrm{p}=0,005)$ и повышенный уровень глики́рованного гемоглобина $\mathrm{HbA}_{1 c}$ определен у носителей генотипов ADRA2Ars 1800544GC+GG (p=0,014).

Выводы: полученные результаты представляют интерес для понимания молекулярных механизмов развития ожирения. Можно предположить, что гены нейротрансмиттерных систем являются важным звеном формирования ожирения.

Исследование частично финансировалось Российским фондом фундаментальных исследований (№20-013-00261 А) и Министерства науки и высшего образования Российской Федерации НИР № АAАA-A16-116020350031-4; биологический материал (ДНК) для исследования взят из коллекции «Коллекция биологических материалов человека ИБГ УНЦ РАН», поддержанной программой биоресурсных коллекций ФАНО России (соглашение №007-030164/2).

Авторы заявляют об отсутствии конфликта интересов.

КЛЮЧЕВЫЕ СЛОВА: ожирение; генетический полиморфизм; гены нейротрансмиттеры; гены воспаления. 